\title{
Influência dos parâmetros de ensaio na determinação da resistência de aderência de revestimentos de argamassa
}

\author{
Influence of testing parameters on the determination of \\ the bond strength of mortar renderings
}

\section{Eliane Betânia Carvalho Costa Helena Carasek}

Eliane Betânia Carvalho

Costa

Escola de Engenharia Civil Universidade Federal de Goiás Praça Universitária, s/n, Bloco A, Sala 11, Setor Universitário Goiânia - GO - Brasil CEP 74605-220 Tel.: (62) 3209-6084

E-mail: elianecosta@usp.br

Helena Carasek Escola de Engenharia Civil Universidade Federal de Goiás E-mail: hcarasek@gmail.com

Recebido em 16/07/09 Aceito em 06/11/09

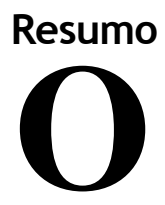

ensaio de resistência de aderência à tração, um dos principais parâmetros para avaliação do desempenho de revestimentos de argamassa, é preconizado por diferentes normas, em âmbito internacional e nacional. No entanto, a existência de parâmetros divergentes ou pouco especificados tem ocasionado alta variabilidade dos resultados para uma mesma situação de ensaio. Assim, o objetivo deste trabalho foi avaliar a influência de alguns parâmetros do ensaio na variabilidade dos resultados de resistência de aderência. Para tanto, o estudo foi elaborado em duas etapas: uma modelagem computacional utilizando o método dos elementos finitos (programa ANSYS ${ }^{\circ}$ ) e outra experimental (em laboratório), com testes de resistência de aderência à tração de revestimentos de argamassa aplicados em placas de concreto, sendo ensaiado um total de 530 corpos de prova. Os resultados obtidos mostram que a geometria e dimensão dos corpos de prova, o procedimento de corte, o tipo de equipamento, a taxa de carregamento e excentricidade do corpo de prova contribuem com a variabilidade dos resultados de aderência. Além disto, constatou-se uma relação direta entre a resistência de aderência à tração e a umidade do revestimento no momento de realização do ensaio.

Palavras-chave: Revestimento. Argamassa. Aderência. Elementos finitos. Normalização.

\section{Abstract}

The testing of tensile bond strength, one of the main parameters to evaluate the performance of mortar renderings, is prescribed by different national and international standards. However, the existence of conflicting or under-specified parameters causes high variability of results for the same test situation. Hence, the aim of this study is to evaluate the influence of certain test parameters in the variability of the results for bond strength. The study was done in two stages: using a computer model using the Finite Element Method (Ansys ${ }^{\circledR}$ program), and an experimental study (in a laboratory), by doing tensile bond strength tests on mortar renderings applied on concrete slabs, with a total of 530 specimens. The results show that the geometry and dimension of the test specimen, the cutting procedure, the equipment type, loading rates and eccentricity contribute to the variability of the results. Additionally, there was a direct relationship between bond strength and the moisture of the rendering at the time the test was undertaken.

Keywords: Rendering. Mortar. Bond. Test method. Finit Element. Sstandard. 


\section{Introdução}

A aderência do revestimento ao substrato é uma das principais propriedades mecânicas para a verificação do desempenho dos sistemas de revestimento. No entanto, trata-se de uma propriedade complexa, pois depende de uma série de fatores relacionados às características dos materiais envolvidos, tanto da argamassa como do substrato, das técnicas de execução e das condições de exposição do revestimento ao ambiente (PALMER; PARSONS, 1934; ANTUNES, 2005)

Não bastasse a complexidade inerente à propriedade, os mecanismos que regem a aderência dos revestimentos no estado endurecido não são completamente entendidos e tampouco, conforme vários pesquisadores, existe ensaio completamente adequado para avaliar a resistência de aderência (WEISS, 1995; SUGO; PAGE; LAWRENCE, 2001; ANTUNES, 2005). Neste sentido, um equipamento foi desenvolvido por Bortoluzzo, em 2000, adaptado da Rilem. O referido equipamento demonstrou-se eficiente, uma vez que é simples e não introduz momento na pastilha fixada à superfície do revestimento de argamassa.

Atualmente, a avaliação quantitativa da aderência de revestimentos de argamassa tem sido realizada por meio da determinação da resistência de aderência à tração. Em âmbito internacional, esse ensaio é executado conforme a metodologia proposta pela Norma Européia EN1015-12 (EUROPEAN COMITTEE FOR STANDARDIZATION, 2000) e no Brasil, mediante as normas da Associação Brasileira de Normas Técnicas NBR 13528 (ABNT, 1995) e NBR 15258 (ABNT, 2005).

Embora haja diferentes normas de consulta pública, o princípio dos métodos não varia e consiste na imposição de um esforço de tração perpendicular ao plano do revestimento, após a delimitação de um corpo de prova. Entretanto, são divergentes ou pouco específicos em alguns parâmetros de ensaio estabelecidos, tais como, geometria, dimensão e técnica de preparo dos corpos de prova, condições de cura, velocidade de aplicação da carga, quantidade mínima dos corpos de prova, bem como a forma da apresentação dos resultados.

Essa padronização insuficiente da metodologia de ensaio tem sido fonte de alta variabilidade dos resultados (CINCOTTO; SILVA; CARASEK, 1995; GONÇALVES, 2004). Pesquisadores e institutos de pesquisa têm apresentado resultados com alta variabilidade para uma mesma situação de ensaio (coeficientes de variação superiores a $30 \%$ ), além de grandes variações de resultados quando laboratórios diferentes realizam o ensaio em um mesmo revestimento.

Diante de tais considerações, o presente estudo propõe investigar os parâmetros de ensaio que interferem na medida dos valores de resistência de aderência à tração visando à obtenção de resultados mais confiáveis e com a menor variabilidade possível. Nesse sentido, a pesquisa foi elaborada em duas etapas distintas: a primeira, uma modelagem computacional, utilizando o programa ANSYS $\AA$, e a segunda experimental, realizada em laboratório, porém interligadas no âmbito das variáveis avaliadas. Para facilitar a compreensão, a seguir estão descritos separadamente as variáveis estudadas, os materiais empregados, a metodologia empregada para cada etapa analisada (numérica e experimental). Posteriormente, são apresentados e discutidos os resultados considerando as variáveis analisadas.

\section{Modelagem computacional}

A modelagem computacional buscou analisar o comportamento elástico linear dos sistemas de revestimento de argamassa quando submetidos a um esforço de tração aplicado, para prever e respaldar os resultados experimentais. Para tanto, foi utilizado o Método dos Elementos Finitos (MEF) a fim de verificar a distribuição de tensões entre as camadas constituintes do sistema.

\section{Variáveis estudadas}

As variáveis, estabelecidas conforme os parâmetros estabelecidos pelas normas EN1015-12 (EUROPEAN COMITTEE FOR STANDARDIZATION, 2000), NBR 13528 (ABNT, 1995) e NBR 15258 (ABNT, 2005), foram:

(a) geometria e dimensão dos corpos de prova: circular $50 \mathrm{~mm}$ e quadrado $100 \mathrm{~mm}$; e

(b) camada de cola: avaliou-se a espessura da camada ( $0 \mathrm{~mm}, 5 \mathrm{~mm}, 7 \mathrm{~mm}, 10 \mathrm{~mm}$ e $12 \mathrm{~mm}) \mathrm{e}$ três tipos de cola, cujas propriedades estão descritas na Tabela 1. Cabe salientar que as espessuras de $7 \mathrm{~mm}, 10 \mathrm{~mm}$ e $12 \mathrm{~mm}$ foram adotadas para testar a validade do modelo, uma vez que na prática esses valores não são atingidos.

As propriedades das colas analisadas se enquadram nas faixas de resina de bases poliéster e epoxídicas, especificadas pelo FIB-Bulletin-14: 2001 (CHASTRE, 2005) e por Agioutantis, 
Stiakakis e Kleftakis (2002). Excentricidade da pastilha: com e sem excentricidade. A pastilha excêntrica pretende simular possíveis imperfeições na execução do ensaio, as quais podem afetar a aderência.

\section{Metodologia}

\section{Definição da geometria e condições de contorno do modelo}

Os modelos foram construídos utilizando o programa ANSYS, versão 6.1, que possui uma vasta biblioteca de elementos finitos disponíveis para os diversos tipos de análise estrutural. Os modelos foram discretizados, empregando-se uma malha bem refinada composta por elementos tridimensionais isoparamétricos (tipo SOLID 65). Este elemento tridimensional possui oito nós com três graus de liberdade cada um, translações em x, y e z, podendo ser utilizado para modelar concreto simples, concreto armado e sistemas equivalentes.

A modelagem do sistema de revestimento foi feita considerando-o composto por um substrato de concreto, com dimensões de $1,00 \mathrm{~m}$ x $1,00 \mathrm{~m} \times$ $0,15 \mathrm{~m}$, engastado nas direções xz e yz, argamassa de revestimento (espessura $25 \mathrm{~mm}$ ), cola e pastilha de alumínio (espessura $10 \mathrm{~mm}$ ). A Figura 1 mostra uma representação esquemática do sistema adotado.

Os modelos analisados foram elaborados conforme as variáveis estudadas. Para a análise da geometria e dimensão dos corpos de prova, a camada de cola não foi considerada. $\mathrm{O}$ estudo da camada de cola e excentricidade da pastilha foi realizado com corpo de prova circular $(50 \mathrm{~mm})$, sendo que para esta última variável foi adotada como condição fixa a cola do tipo 1 com espessura de $5 \mathrm{~mm}$.

\begin{tabular}{c|c|c}
\hline Cola & $\begin{array}{c}\text { Módulo de } \\
\text { elasticidade } \\
\text { (GPa) }\end{array}$ & $\begin{array}{c}\text { Coeficiente de } \\
\text { Poisson }\end{array}$ \\
\hline $\mathbf{1}$ & 0,35 & 0,35 \\
\hline $\mathbf{2}$ & 0,50 & 0,35 \\
\hline $\mathbf{3}$ & 0,35 & 0,40 \\
\hline
\end{tabular}

Tabela 1 - Propriedades dos tipos de cola analisados

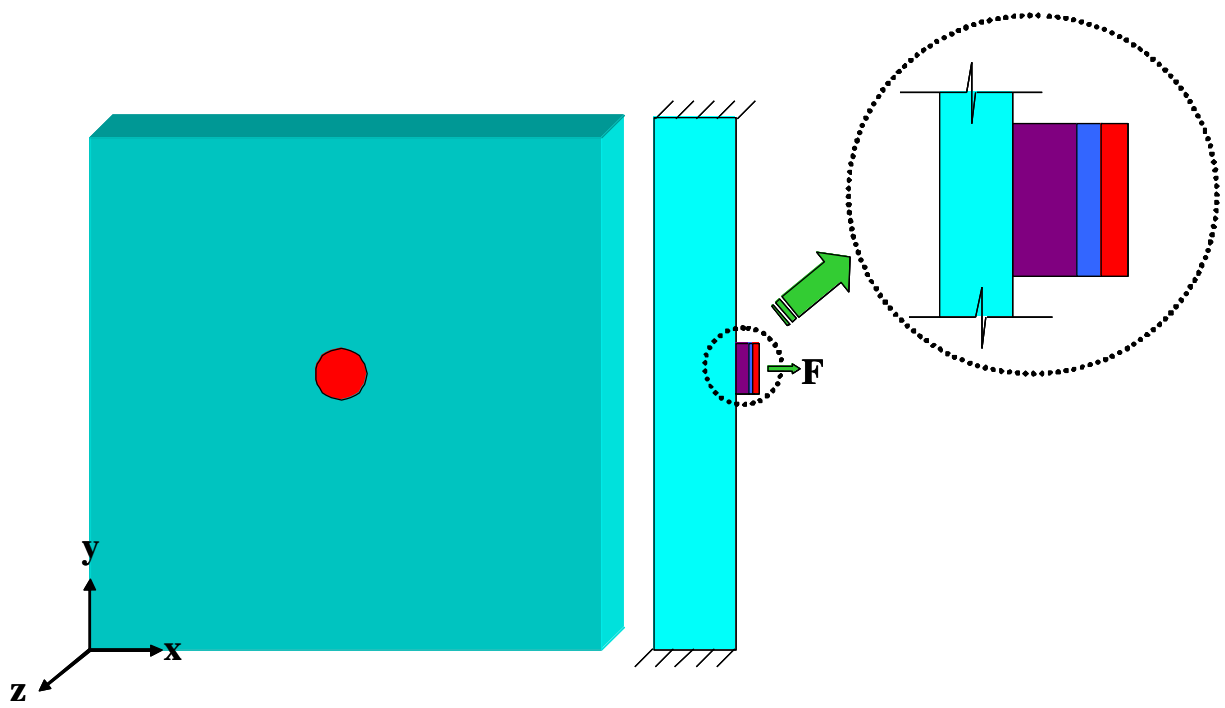

Figura 1 - Composição do sistema de revestimento adotado para a construção dos modelos 
Além destes fatores, para a verificação da excentricidade da pastilha considerou-se uma seção circular com diâmetro de $10 \mathrm{~mm}$ e espessura de $25 \mathrm{~mm}$ (Figura 2), com mesmas propriedades mecânicas da pastilha de alumínio, simulando a peça de encaixe entre o equipamento e a pastilha durante a realização do ensaio, de forma a facilitar a determinação do ponto de aplicação da carga.

Para representar a carga aplicada no ensaio, aplicou-se no corpo de prova uma tensão uniformemente distribuída igual a 0,20 $\mathrm{MPa}$. Entretanto, para verificação da forma de aplicação da carga (com e sem excentricidade), o carregamento foi distribuído em uma região circular de diâmetro $10 \mathrm{~mm}$. Nesses casos, a carga distribuída aplicada foi proporcional à área do parafuso, ou seja, $5 \mathrm{MPa}$, para que ao ser transmitida à pastilha pudesse obter um valor igual a 0,20 $\mathrm{MPa}$, correspondendo a mesma força aplicada aos demais sistemas.

Para representar a carga aplicada no ensaio, aplicou-se no corpo de prova uma tensão uniformemente distribuída igual a 0,20 $\mathrm{MPa}$. Entretanto, para verificação da forma de aplicação da carga (com e sem excentricidade), o carregamento foi distribuído em uma região circular de diâmetro $10 \mathrm{~mm}$. Nesses casos, a carga distribuída aplicada foi proporcional à área do parafuso, ou seja, $5 \mathrm{MPa}$, para que ao ser transmitida à pastilha pudesse obter um valor igual a 0,20 $\mathrm{MPa}$, correspondendo a mesma força aplicada aos demais sistemas.

\section{Propriedades atribuídas aos elementos}

O comportamento dos materiais envolvidos no sistema de revestimento depende essencialmente de algumas propriedades, sendo estas fornecidas e especificadas para cada elemento finito usado na modelagem do sistema. Os valores e as variações adotados foram atribuídos de acordo com a literatura consultada, (CARASEK, 1996; AGIOUTANTIS; STIAKAKIS; KLEFTAKIS, 2002; VAN VLACK, 2000). A Tabela 2 apresenta as propriedades dos materiais envolvidos nos sistemas estudados.

Os materiais foram considerados isotrópicos, ou seja, com as mesmas propriedades nas três direções ortogonais. Além disso, a argamassa de revestimento foi idealizada como um material fisicamente linear, ou seja, com a relação entre as tensões e as deformações absolutamente linear.

\section{Análise dos resultados}

Com o objetivo de facilitar a compreensão dos resultados, as figuras fornecidas pelo programa ANSYS $®$ foram padronizadas para cada situação analisada, ou seja, tensões iguais estão apresentadas na mesma cor. Além destes resultados, também foram gerados gráficos, com base em cortes realizados no sistema, os quais mostram a distribuição das tensões geradas na interface argamassa-substrato (Figura 3).

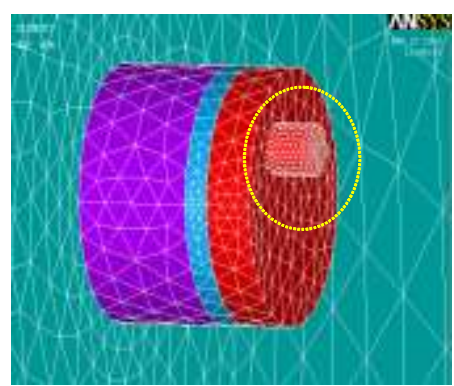

(a)

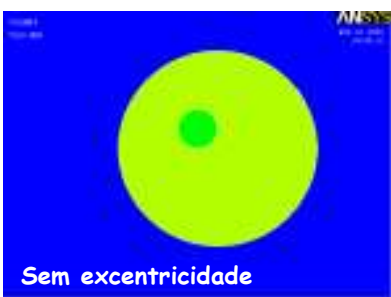

(b)

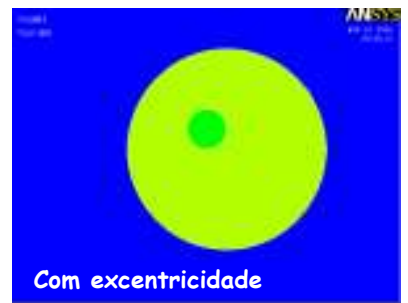

(c)

Figura 2 - Modelos construídos para verificação da excentricidade da pastilha: vista lateral do sistema, destacando o parafuso (a) e vista frontal do modelo sem excentricidade (b) e com excentricidade (c)

\begin{tabular}{l|c|c}
\hline \multicolumn{1}{c|}{ Materiais } & \multicolumn{1}{|c}{$\begin{array}{c}\text { Módulo de } \\
\text { elasticidade (GPa) }\end{array}$} & $\begin{array}{c}\text { Coeficiente de } \\
\text { Poisson }\end{array}$ \\
\hline Concreto (substrato) & 21 & 0,20 \\
\hline Argamassa (revestimento) & 1 & 0,20 \\
\hline Alumínio (pastilha) & 70 & 0,33 \\
\hline
\end{tabular}

Tabela 2 - Propriedades atribuídas aos elementos 


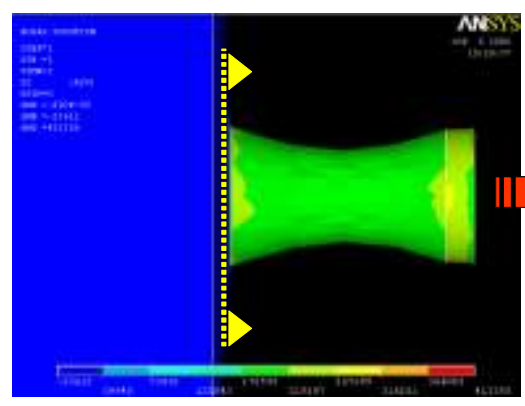

(a)

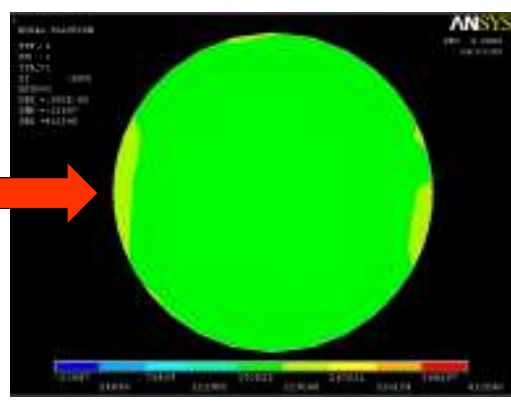

(b)

Figura 3 - Representação esquemática do corte realizado na interface substrato/argamassas (a) e distribuição das tensões na interface substrato/argamassa (b)

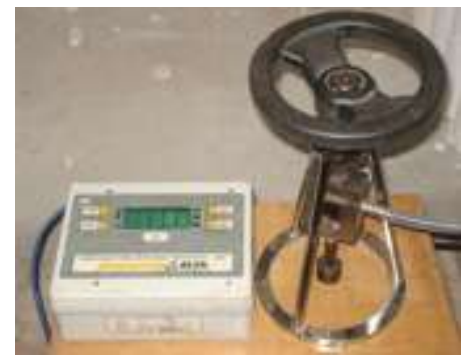

(a) Dinamômetro de tração montado pela empresa Consultare com célula de carga e indicador de pesagem do fabricante Alfa instrumentos

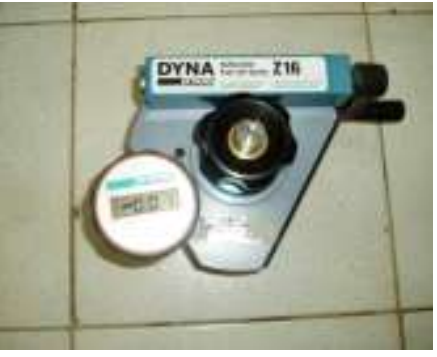

(b) Dinamômetro de tração montado pela Dyna Proceq

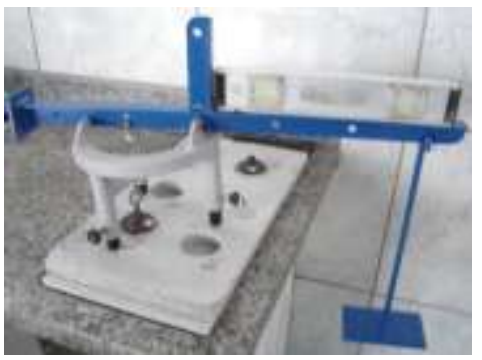

(c) Braço de alavanca adaptado do modelo EPUSP/ENCOL

Figura 4 - Equipamentos empregados na realização do ensaio de resistência de aderência à tração

\begin{tabular}{l|c|c|c}
\hline \multirow{2}{*}{ Características } & A & B & C \\
\cline { 2 - 4 } & Hidráulico-manual & Hidráulico-manual & Braço de alavanca \\
\hline $\begin{array}{l}\text { Princípio de } \\
\text { funcionamento }\end{array}$ & $1 \mathrm{kN}$ & $6 \mathrm{kN}$ & Variável \\
\hline Capacidade de carga & Digital & Digital & - \\
\hline Escala & $0,05 \mathrm{kgf}$ & $0,01 \mathrm{~N} / \mathrm{mm}^{2}$ & $0,38 \mathrm{~kg}$ \\
\hline Resolução & Consultare & Proceq & Dinâmica industrial \\
\hline Fabricante & Consultare & Dyna Z6 & Adaptado EPUSP/Encol \\
\hline Modelo & $3,5+1,9^{1}$ & $3,5 \mathrm{~kg}$ & $2,3 \mathrm{~kg}{ }^{2}$ \\
\hline Massa &
\end{tabular}

Tabela 3 - Características dos equipamentos utilizados

A falta de simetria dos resultados obtidos se justifica pela forma como ocorreu a geração da malha, ou seja, os elementos foram criados livremente pelo programa e, muitas vezes, não se apresentam com distribuição simétrica em relação à interface, conforme ilustrado na Figura 3(b).

\section{Parte experimental}

O programa experimental foi desenvolvido em laboratório e contemplou diferentes parâmetros pré-fixados por normas de consulta pública para o ensaio de resistência de aderência à tração com o intuito de identificar as principais fontes de variabilidade.

\section{Variáveis estudadas}

Foram estudadas as seguintes variáveis:

(a) procedimento de corte do revestimento: seco e com água;

(b) geometria e dimensão dos corpos de prova: circular $50 \mathrm{~mm}$ e quadrado $100 \mathrm{~mm}$;

(c) tipo de cola: base epóxi e base poliéster. $\mathrm{O}$ estudo do adesivo é importante, pois pode influenciar no tipo de ruptura do sistema analisado, ocasionando falhas durante a execução do ensaio. Isso foi constatado por Bortoluzzo (2000) analisando diferentes tipos de cola. $\mathrm{O}$ referido autor encontrou dificuldades em obter um tipo de 
cola satisfatório ao conjunto argamassa/substrato utilizado devido à elevada resistência mecânica;

(d) excentricidade da pastilha: com e sem excentricidade;

(e) tipo de equipamento: foram testados três equipamentos com princípios de funcionamento, resolução e escalas diferentes (Figuras 4 a, b e c), cujas principais características estão apresentadas na Tabela 3. A seleção dos equipamentos foi feita com respaldo em duas etapas: a primeira, por meio de um ensaio piloto realizado em obra, cujos resultados foram publicados no ENTAC (COSTA; DUARTE; CARASEK, 2006) e a segunda, consistiu na identificação dos principais tipos de equipamentos utilizados no Brasil, por meio da aplicação de questionários a laboratórios brasileiros e dados coletados na literatura. Cabe ressaltar que o braço de alavanca, embora não seja utilizado por laboratórios, foi adotado por apresentar menores coeficientes de variação (BORTOLUZZO, 2000; COLLANTES, 1998); e

(f) Taxa de carregamento: máxima (>25 N/s) e mínima $(\leq 25 \mathrm{~N} / \mathrm{s})$.

\section{Condições fixas}

Alguns parâmetros foram considerados constantes em todo o estudo. Estes foram: o tipo de substrato, a composição, o processo de produção e a forma de lançamento da argamassa utilizada, que serão descritos posteriormente. Outros parâmetros foram adotados de acordo com a variável analisada como mostra a Tabela 4.

\section{Materiais}

A seguir são descritos os materiais utilizados:

(a) substrato: placas de substrato-padrão em concreto, com dimensões de $25 \mathrm{~cm}$ x $50 \mathrm{~cm}$ e espessura de $20 \mathrm{~mm}$, confeccionadas e ensaiadas em acordo com os procedimentos da ABNT (2004) NBR 14082;

(b) tipo de argamassa: industrializada para uso em revestimentos externos e internos, composta por cimento Portland, areia e aditivos; e

(c) tipo de cola: dois tipos, cujas características são exibidas na Tabela 5.

\begin{tabular}{|c|c|}
\hline Variáveis & Condições fixas \\
\hline $\begin{array}{l}\text { Tipo de corte do corpo de prova: } \\
\text { - Seco; } \\
\text { - Com água. }\end{array}$ & $\begin{array}{l}\text { - Geometria e dimensão do corpo de prova: circular } 50 \mathrm{~mm} \text {; } \\
\text { - Tipo de cola: base poliéster; } \\
\text { - Tipo de equipamento: A; } \\
\text { - Pastilha sem excentricidade; } \\
\text { - Taxa de carregamento constante. }\end{array}$ \\
\hline $\begin{array}{l}\text { Geometria e dimensão dos corpos de } \\
\text { prova: } \\
\text { - Circular: } \Phi=5 \mathrm{~cm} \text {; } \\
\text { - Quadrado: e } \mathrm{L}=10 \mathrm{~cm} .\end{array}$ & $\begin{array}{l}\text { - Tipo de corte: com água; } \\
\text { - Tipo de cola: base poliéster; } \\
\text { - Tipo de equipamento: A; } \\
\text { - Pastilha sem excentricidade; } \\
\text { - Taxa de carregamento constante. } \\
\end{array}$ \\
\hline $\begin{array}{l}\text { Tipo de cola: } \\
\text { - Base epóxi; } \\
\text { - Base poliéster. }\end{array}$ & $\begin{array}{l}\text { - Tipo de corte: com água; } \\
\text { - Geometria e dimensão do corpo de prova: circular } 50 \mathrm{~mm} \text {; } \\
\text { - Tipo de equipamento: A; } \\
\text { - Pastilha sem excentricidade; } \\
\text { - Taxa de carregamento constante. }\end{array}$ \\
\hline $\begin{array}{l}\text { Excentricidade da pastilha: } \\
\text { - Sem excentricidade; } \\
\text { - Com excentricidade. }\end{array}$ & $\begin{array}{l}\text { - Tipo de corte: com água; } \\
\text { - Geometria e dimensão do corpo de prova: circular } 50 \mathrm{~mm} \text {; } \\
\text { - Tipo de cola: base poliéster; } \\
\text { - Tipo de equipamento: B; } \\
\text { - Taxa de carregamento constante. }\end{array}$ \\
\hline $\begin{array}{l}\text { Tipo de equipamento: } \\
\text { - Dinamômetro de tração: A e B; } \\
\text { - Alavanca de tração: C. }\end{array}$ & $\begin{array}{l}\text { - Tipo de corte: com água; } \\
\text { - Geometria e dimensão do corpo de prova: circular } 50 \mathrm{~mm} \text {; } \\
\text { - Tipo de cola: base poliéster; } \\
\text { - Pastilha sem excentricidade; } \\
\text { - Taxa de carregamento constante. }\end{array}$ \\
\hline $\begin{array}{l}\text { Taxa de carregamento: } \\
\text { - Máxima: > } 25 \mathrm{~N} / \mathrm{s} \\
\text { - Mínima: } \leq 25 \mathrm{~N} / \mathrm{s}\end{array}$ & $\begin{array}{l}\text { - Tipo de corte: com água; } \\
\text { - Geometria e dimensão do corpo de prova: circular } 50 \mathrm{~mm} \text {; } \\
\text { - Tipo de cola: base poliéster; } \\
\text { - Tipo de equipamento: A; } \\
\text { - Pastilha sem excentricidade. }\end{array}$ \\
\hline
\end{tabular}

Tabela 4 - Variáveis e condições fixas dos modelos estudados 


\begin{tabular}{c|c|c}
\hline Características & Resina Poliéster & Resina Epóxi \\
\hline Estado físico & Líquido menos viscoso & Líquido mais viscoso \\
\hline Densidade (g/cm $\mathbf{c m}^{\mathbf{3}}$ & $1,60-1,70$ & 1,74 \\
\hline Gel time $(\mathbf{m i n})$ & $5-10$ & 78,08 \\
\hline Viscosidade $(\mathbf{C p s})$ & - & 26500 \\
\hline Base química & Cargas minerais e resinas de poliéster & Bisfenol e poliamidas \\
\hline
\end{tabular}

Obs.: informações obtidas nos departamentos de assistência técnica dos fabricantes

Tabela 5 - Características das colas utilizadas

\section{Metodologia}

\section{Preparo dos revestimentos de argamassa}

As argamassas foram preparadas em betoneira de eixo inclinado, pré-umedecida, com capacidade de 120 litros, sendo cada mistura efetuada com dois sacos de argamassa (com $50 \mathrm{~kg}$ cada) empregandose 15,2 litros de água, com tempo de mistura entre 8 min e 10 min.

\section{Caracterização das argamassas}

Para a caracterização das argamassas foram realizados ensaios no estado fresco e endurecido; os métodos de ensaios e os resultados são apresentados na Tabela 6.

\section{Aplicação da argamassa}

Previamente a aplicação da argamassa era feita uma limpeza superficial nos substratos para a retirada de poeira e outros materiais que pudessem prejudicar a aderência argamassa-substrato. Após este procedimento, os substratos eram colocados na vertical e procedia-se o lançamento das argamassas.

A forma de lançamento da argamassa ao substrato é dos um fatores que interferem no desempenho do revestimento, principalmente no que se refere ao mecanismo de aderência. Alguns autores mencionam que o lançamento manual gera grande variabilidade da resistência de aderência por estar diretamente relacionada à habilidade, conhecimento e ergonomia do pedreiro (GOODWIN; WEST, 1982; MURRAY, 1983; GONÇALVES, 2004; NEVES et al., 1995; CARASEK, 2007).

Para minimizar esta variabilidade, optou-se pela utilização de um sistema de projeção mecânico. A projeção foi feita com pressão igual a $0,77 \mathrm{MPa}$ (110 psi), na forma de filetes contínuos de baixo para cima, guardando uma distância de $30 \mathrm{~cm}$ das placas a serem revestidas.

A espessura do revestimento foi fixada em $25 \pm 2$ mm e controlada com auxílio de uma guia metálica fixada sobre o painel. Após a aplicação da argamassa, aguardava-se o ponto de sarrafeamento do revestimento. Decorrido este tempo de espera, o pedreiro cortava a argamassa excedente por meio de uma régua de alumínio. Posteriormente, executava-se o desempeno da superfície com uma desempenadeira de madeira, o acabamento final era realizado com uma espuma umedecida e então com cuidado as placas revestidas eram separadas por meio de um corte superficial com espátula.

Após 24 horas da aplicação da argamassa, as placas revestidas eram cuidadosamente transportadas para um tanque de água, onde permaneceram durante o período de cura.

\section{Cura dos revestimentos}

As placas revestidas com argamassa foram curadas em tanque de água, durante catorze dias. Este procedimento foi adotado, uma vez que o único aglomerante da argamassa de revestimento é o cimento Portland, podendo, desta forma, ser submetido a uma cura submersa, e garantir um maior controle da variável, evitando variações indesejáveis em relação as condições de umidade e temperatura. Ao serem retiradas do tanque, as placas eram mantidas em ambiente de laboratório até a data de realização do ensaio. Os ensaios foram realizados nos revestimentos com idade igual a $82 \pm 3$ dias.

\section{Determinação da resistência de aderência à tração}

Para cada variável analisada foram preparados trinta corpos de prova, sendo distribuídos seis em cada placa de forma aleatória, mantendo-se um espaço mínimo de $50 \mathrm{~mm}$ entre os corpos de prova e pelo menos $20 \mathrm{~mm}$ das bordas, com o intuito de neutralizar a variabilidade associada aos materiais e a confecção dos revestimentos. Assim, foram preparadas cinco placas para situação analisada, resultando um total de 105 placas revestidas com 530 corpos de prova ensaiados.

Os cortes foram realizados previamente à colagem das pastilhas, independente da geometria e dimensão dos corpos de prova. Para evitar 
vibrações, os corpos de prova circulares, foram cortados por um serra-copo acoplada a uma furadeira de coluna e os quadrados com serramármore, cujo disco de corte possui diâmetro igual a $110 \mathrm{~mm}$ e potência de 1300 w. Os cortes com água foram executados com auxílio de uma mangueira.

Após o corte, as placas permaneciam ao ar por 24 horas para posterior colagem dos corpos de prova.

A excentricidade de carga foi examinada por meio do deslocamento da pastilha, do centro do furo, feito anteriormente com o serra-copo. As Figuras $5 a$ e $5 b$ ilustram os corpos de prova sem excentricidade e excêntricos.

O tempo aguardado para a secagem da cola era de no mínimo $1 \mathrm{~h}$ para o adesivo de base poliéster e $12 \mathrm{~h}$ para a resina epóxi. Depois desse período eram realizados os ensaios de resistência de aderência à tração.

O ensaio de resistência de aderência à tração foi executado com um dos equipamentos descritos no item 3.1, por meio da imposição de um carregamento axial de tração à pastilha previamente colada ao revestimento. Para reduzir a variabilidade de operação, alguns cuidados foram considerados: o ensaio foi executado sempre na posição horizontal, mantendo-se sempre o eixo de aplicação da carga perpendicular ao revestimento; evitaram-se trepidações do equipamento enquanto estivesse conectado à pastilha.
Após a ruptura, anotava-se, para cada corpo de prova ensaiado, a carga e a porcentagem do tipo de ruptura.

\section{Análise dos resultados}

Os resultados obtidos foram submetidos à análise de variâncias (ANOVA) para determinação dos fatores associados às variáveis estudadas. Após esta análise foi realizada uma comparação múltipla de médias (testes estatísticos de Duncan) para as variáveis com mais de dois tratamentos, com o objetivo de agrupar as médias que diferiam significativamente entre si, a separação dos grupos sob o ponto de vista da estatística será indicada neste trabalho por linhas verticais tracejadas nos gráficos de box plot.

\section{Resultados e discussões}

\section{Influência do procedimento de corte}

A Tabela 7 exibe a análise de variância dos resultados experimentais de resistência de aderência para os cortes realizados a seco e com água. A análise mostrou que não há diferenças significativas entre os tipos de corte executados. Entretanto, percebe-se maior variação dos resultados para os cortes executados a seco (Figura 6).

\begin{tabular}{|c|c|c|c|c|c|}
\hline & Característic & rminada & Método de ensaio & $\mathbf{n}$ & Resultados médios \\
\hline \multirow{3}{*}{$\begin{array}{l}\text { Estado } \\
\text { fresco }\end{array}$} & \multicolumn{2}{|c|}{ Densidade de massa } & NBR 13278/1995 & 15 & $1,69 \mathrm{~g} / \mathrm{cm}^{3}$ \\
\hline & \multicolumn{2}{|c|}{$\begin{array}{l}\text { Consistência - penetração do } \\
\text { cone }\end{array}$} & ASTM C-780/1996 & 15 & $40 \mathrm{~mm}$ \\
\hline & \multicolumn{2}{|c|}{$\begin{array}{c}\text { Teor de ar } \\
\text { método pressométrico }\end{array}$} & NBR 11686/1990 & 12 & $20 \%$ \\
\hline \multirow{3}{*}{$\begin{array}{c}\text { Estado } \\
\text { endure } \\
\text { cido }\end{array}$} & \multirow{3}{*}{$\begin{array}{l}\text { Resistência à } \\
\text { compressão }\end{array}$} & 7 dias & \multirow{3}{*}{ NBR 13279/1995 } & \multirow{3}{*}{4} & $3,0 \mathrm{MPa}$ \\
\hline & & 28 dias & & & 3,6 MPa \\
\hline & & 90 dias & & & $4,4 \mathrm{MPa}$ \\
\hline
\end{tabular}

Tabela 6 - Caracterização das argamassas no estado fresco e endurecido

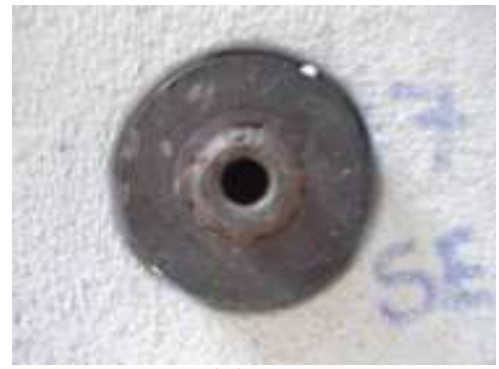

(a)

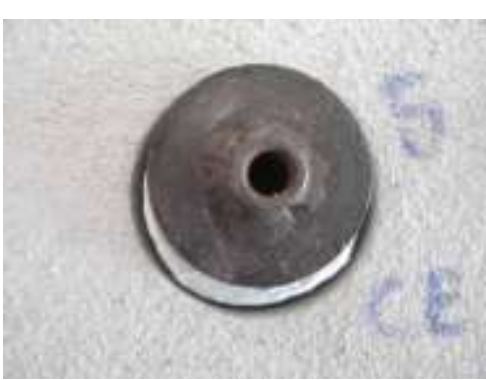

(b)

Figura 5 - Colagem das pastilhas sobre os corpos de prova (a) sem excentricidade (b) com excentricidade 


\begin{tabular}{|c|c|c|c|c|c|c|}
\hline Efeito & SQ & GL & MQ & $\mathbf{F}_{\text {cal }}$ & $\mathbf{F}_{\text {tab }}$ & Resultado \\
\hline Entre Grupos & 0,01 & 1 & 0,01 & 0,41 & 4,08 & Não-significativo \\
\hline Dentro Grupos (Resíduos) & 1,28 & 40 & 0,03 & - & - & - \\
\hline Total & 1,29 & 41 & - & - & - & - \\
\hline $\begin{array}{l}\text { soma dos quadrados } \\
\text { graus de liberdade } \\
\text { média dos quadrados }\end{array}$ & & & & & & \\
\hline
\end{tabular}

Tabela 7 - Resultados da análise de variância realizada com os valores de resistência de aderência à tração para os cortes executados a seco e com água

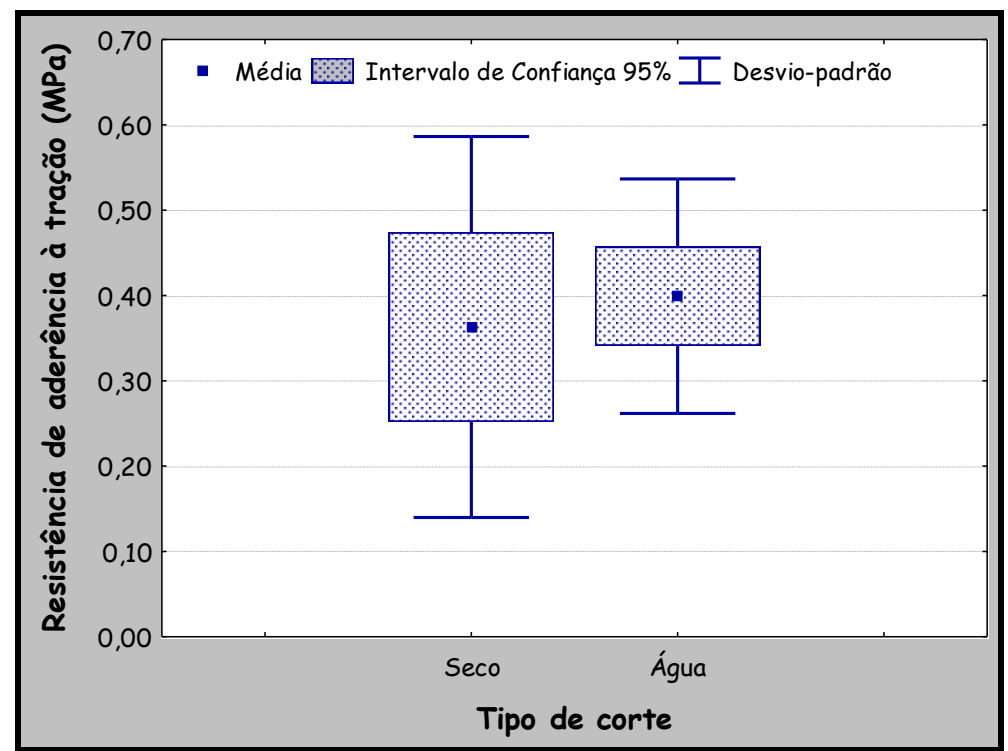

Figura 6 - Valores médios de resistência de aderência e coeficientes de variação, aos 48 dias, para os cortes realizados com água e a seco

A alta variabilidade obtida para o corte a seco pode ser explicada por dois fatores: primeiro, a fragilidade da ligação entre a argamassa-substrato evidenciada pela quantidade de corpos de prova arrancados durante a execução do corte $(22 \%)$; segundo, pela indução de tensões laterais ao corpo de prova durante a realização do mesmo.

Outro fator que pode interferir nos valores de resistência de aderência e na variabilidade dos resultados é a umidade ${ }^{1}$ absorvida pelo revestimento no momento de realização do ensaio. Desse modo, procurou-se estabelecer uma correlação entre a resistência de aderência e a umidade do revestimento, conforme ilustra a Figura 7.

A Figura 7 mostra que a resistência de aderência à tração tende a diminuir linearmente à medida que

${ }^{1} \mathrm{O}$ teor de umidade foi determinado para cada corpo de prova ensaiado, estes eram pesados e colocados em estufa à temperatura de $105 \pm 5^{\circ} \mathrm{C}$ por 24 horas. Em seguida, determinavase a massa seca e procedia-se o cálculo do teor de umidade à pastilha. Cada valor apresentado na Figura 7 representa a média de três corpos de prova por placa e situação analisada (corte seco e com água). se aumenta a umidade absorvida pelo revestimento. Algumas pesquisas mostram um comportamento diferenciado quando avaliado revestimentos na condição seca ou saturada. Candia e Franco (1998) analisando a preparação de corpos de prova para o ensaio de resistência ao cisalhamento obtiveram resultados superiores para o revestimento na condição seca. Essa tendência também foi observada por Bonaldo, Barros e Lourenço (2005) e Costa (2007) durante a realização do ensaio de resistência de aderência à tração.

Carasek et al. (2008) analisando três condições distintas de umidade (seco, intermediária e saturado) em revestimentos aplicados sobre base cerâmica observaram que à medida que se aumenta o teor de umidade do revestimento no momento de realização dos ensaios há uma redução nos valores de resistência de aderência à tração, resistência superficial e permeabilidade e absorção de água. 


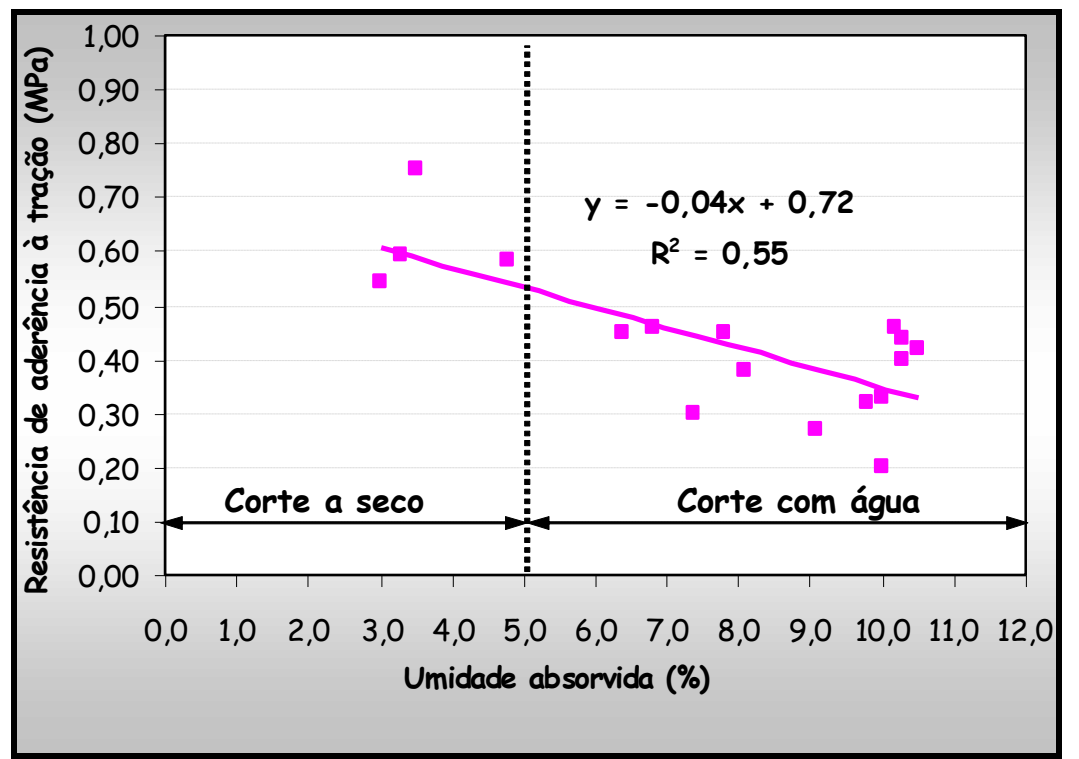

Figura 7 - Resistência de aderência média em função da umidade absorvida pelo revestimento

Bonaldo, Barros e Lourenço (2005) salientam que quando a superfície do substrato está umedecida ou saturada, no momento de realização do ensaio de arrancamento, há a formação de um filme de água na interface que tende a reduzir a resistência de aderência entre os materiais de base cimentícia. Segundo Li (2004) este comportamento não é completamente entendido, acredita-se que a perda de resistência ocorre devido à expansão do C-S-H pela adsorção da água, oriunda da umidade presente no material.

Neste sentido, para a obtenção de resultados mais confiáveis, a ASTM C 39 (AMERICAN SOCIETY FOR TESTING AND MATERIALS, 2001) reconhece o efeito do teor de umidade especificando que o ensaio de resistência à compressão de corpos de prova cilíndricos de concreto devem ser ensaiados na condição saturada, por esta representar a pior condição de resistência, além de ser mais fácil de ser executada. Tendo em vista que para a obtenção de uma condição seca do material, valores exatos de umidade, há necessidade de equipamentos especiais que não poderiam ser reproduzidos em obra.

\section{Influência da geometria e dimensão dos corpos de prova}

A Figura 8 apresenta o resultado da modelagem computacional para as duas geometrias e dimensões testadas. Nota-se que existe uma concentração de tensões nas extremidades do corpo de prova quadrado.
Essa concentração de tensões nos cantos do corpo de prova quadrado pode ser explicada de forma similar ao que ocorre a uma barra quadrada submetida à torção. De acordo com Beer e Johnston Júnior. (1996), as seções transversais deste tipo de barra não se mantêm planas, ao serem submetidas a momento de torção, perdem sua forma inicial, o que provoca um enrijecimento nos cantos e conseqüiente elevação das tensões. Já nas barras circulares, todas as seções transversais se mantêm planas e conservam a sua forma devido a axissimetria.

A Tabela 8 apresenta os resultados da análise de variâncias obtida para os corpos de prova ensaiados visando analisar a influência da geometria e dimensão.

Submetendo-se os resultados experimentais, demonstrados na Tabela 8, ao teste de Duncan, observa-se a formação de dois grupos distintos, como expõe a Figura 9.

Os resultados confirmam a tendência dos corpos de prova circulares apresentarem maiores valores de resistência de aderência em relação aos quadrados. Isto ocorre porque eles apresentam menores valores de tensão na argamassa e não possuem concentração destas nos bordos, na região de interface, conforme mostrado na Figura 8. Observou-se uma redução de $52 \%$ da resistência dos corpos de prova quadrado. Resultados experimentais semelhantes também foram encontrados por Gonçalves (2004), com uma diferença de $58 \%$ da resistência de aderência para as duas geometrias. 


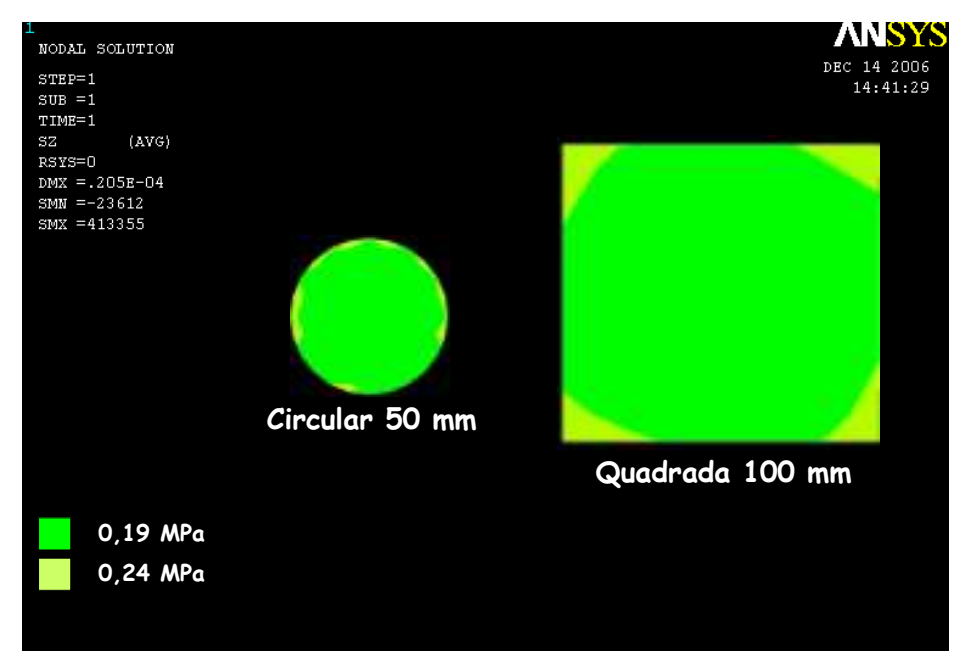

Figura 8 - Distribuição de tensões na interface argamassa-substrato para corpos de prova com geometria e dimensões distintas

\begin{tabular}{c|c|c|c|c|c|c}
\hline Efeito & SQ & GL & MQ & $\mathbf{F}_{\text {cal }}$ & $\mathbf{F}_{\text {tab }}$ & Resultado \\
\hline Entre Grupos & 1,10 & 1 & 1,10 & 64,74 & 4,01 & Significativo \\
\hline Dentro Grupos (Resíduos) & 0,99 & 58 & 0,02 & - & - & - \\
\hline Total & $\mathbf{2 , 0 9}$ & $\mathbf{5 9}$ & - & - & - & - \\
\hline
\end{tabular}

Legenda:

SQ: soma dos quadrados

GL: graus de liberdade

MQ: média dos quadrados

F: parâmetro de Fisher para o teste de significância dos efeitos

Tabela 8 - Resultados da análise de variância realizada com os valores de resistência de aderência à tração para corpos de prova com geometria e dimensão diferentes

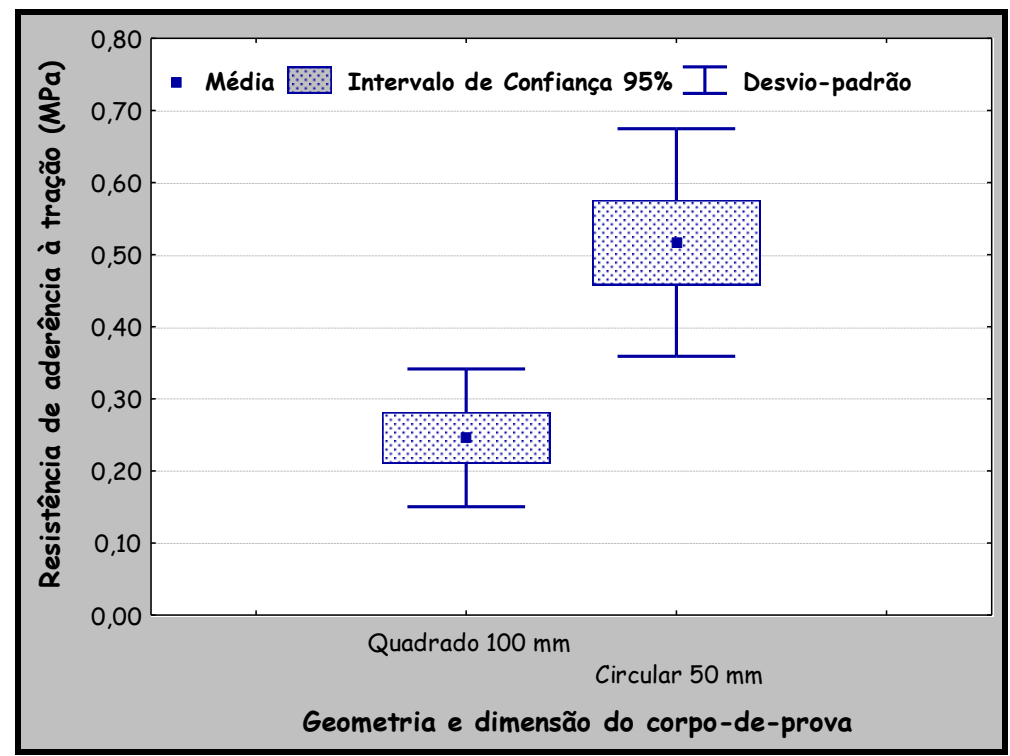

Figura 9 - Valores médios globais de resistência de aderência à tração (82 \pm 3 dias) em função da geometria e dimensão do corpo de prova 


\section{Influência da camada de cola}

Para a colagem da pastilha no revestimento, as normas vigentes (EUROPEAN COMITTEE FOR STANDARDIZATION, 2000; ABNT, 2005) prescrevem cola à base de resina epóxi, sem qualquer menção sobre as propriedades da resina ou sobre a espessura a ser empregada. Por meio da Figura 10, obtida na modelagem computacional, pode-se verificar que a camada de cola exerce influência na distribuição de tensões. Observa-se a formação de dois grupos, o primeiro constituído pelo sistema sem cola e cola $5 \mathrm{~mm}$, e o segundo formado pelas espessuras de $7 \mathrm{~mm}, 10 \mathrm{~mm} \mathrm{e}$ $12 \mathrm{~mm}$.

No primeiro grupo não há a formação de uma envoltória de tensões elevadas, e no outro grupo a membrana de tensões elevadas possui a mesma porcentagem de área, uma em relação às outras. Isso ocorre porque o coeficiente de Poisson da cola é superior e o módulo de elasticidade inferior aos das camadas de argamassa e substrato, permitindo maiores deformações (estrangulamento da seção).
Em relação ao tipo de cola, nota-se, na Figura 11, que não há diferença de tensões para os três tipos de cola analisados.

Assim como constatado na modelagem computacional, a análise estatística dos resultados de laboratório também demonstrou que os tipos de adesivos empregados nesta pesquisa, não exercem influência significativa nos valores de resistência de aderência à tração (Tabela 9). Isto porque estes materiais apresentam propriedades mecânicas similares.

No que diz respeito aos valores de resistência de aderência à tração e coeficientes de variação, os resultados não houve diferenciação significativa para os dois tipos de cola utilizados, conforme mostra Figura 12.

Embora o tipo de cola não tenha se mostrado influente nos valores de resistência de aderência, ao realizar o ensaio deve-se utilizar um material de boa qualidade para evitar rupturas na cola ou na interface argamassa-cola.

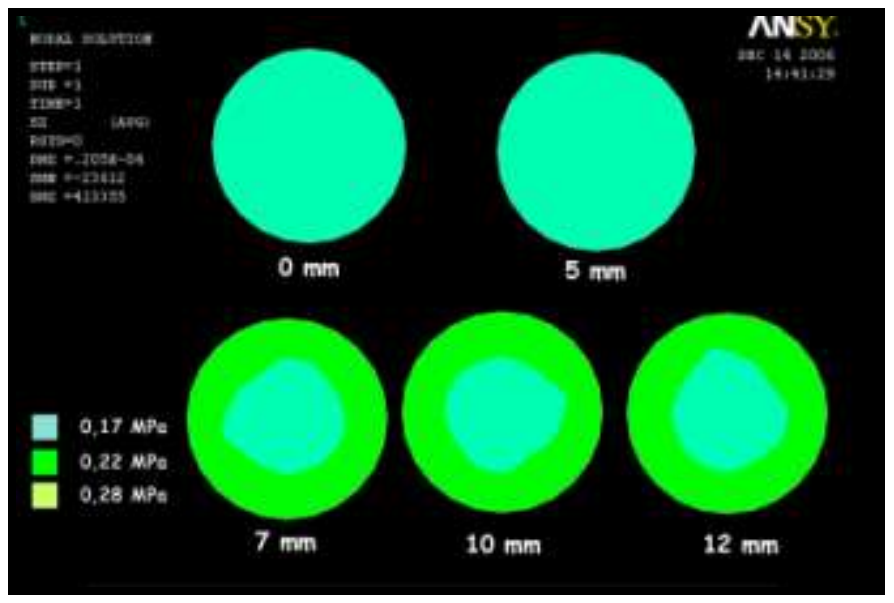

Figura 10 - Distribuição das tensões na interface entre argamassa e substrato para diferentes espessuras da camada de cola

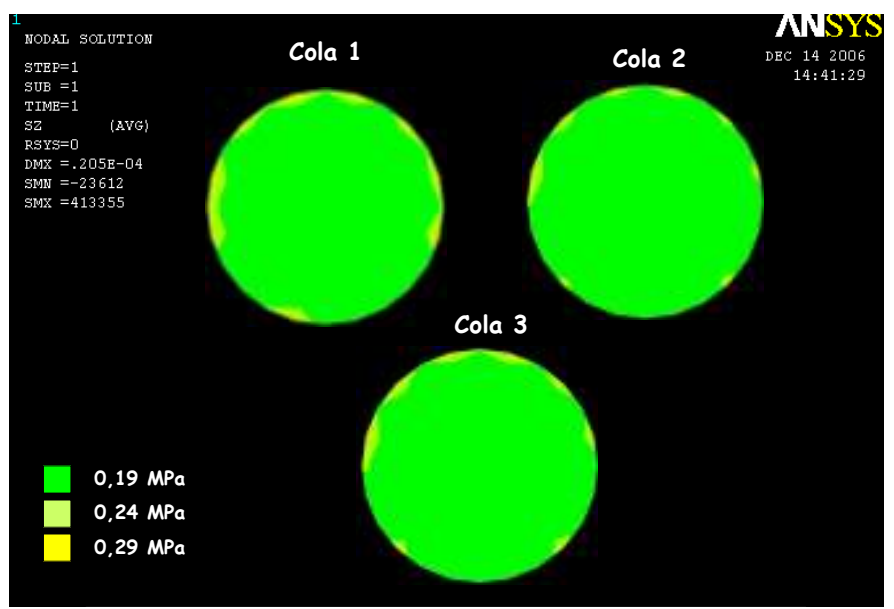

Figura 11 - Distribuição das tensões na interface entre argamassa e substrato para os três tipos de cola estudados com espessura de $5 \mathrm{~mm}$ 


\begin{tabular}{|c|c|c|c|c|c|c|}
\hline Efeito & SQ & GL & MQ & $\mathbf{F}_{\text {cal }}$ & $F_{\text {tab }}$ & Resultado \\
\hline Entre Grupos & 0,00 & 1 & 0,00 & 0,05 & 4,05 & Não-significativo \\
\hline Dentro Grupos (Resíduos) & 0,80 & 47 & 0,02 & - & - & - \\
\hline Total & $\mathbf{0 , 8 0}$ & 48 & - & - & - & - \\
\hline
\end{tabular}

Tabela 9 - Resultados da análise de variância realizada com os valores de resistência de aderência à tração os tipos de cola utilizados (epóxi e poliéster)

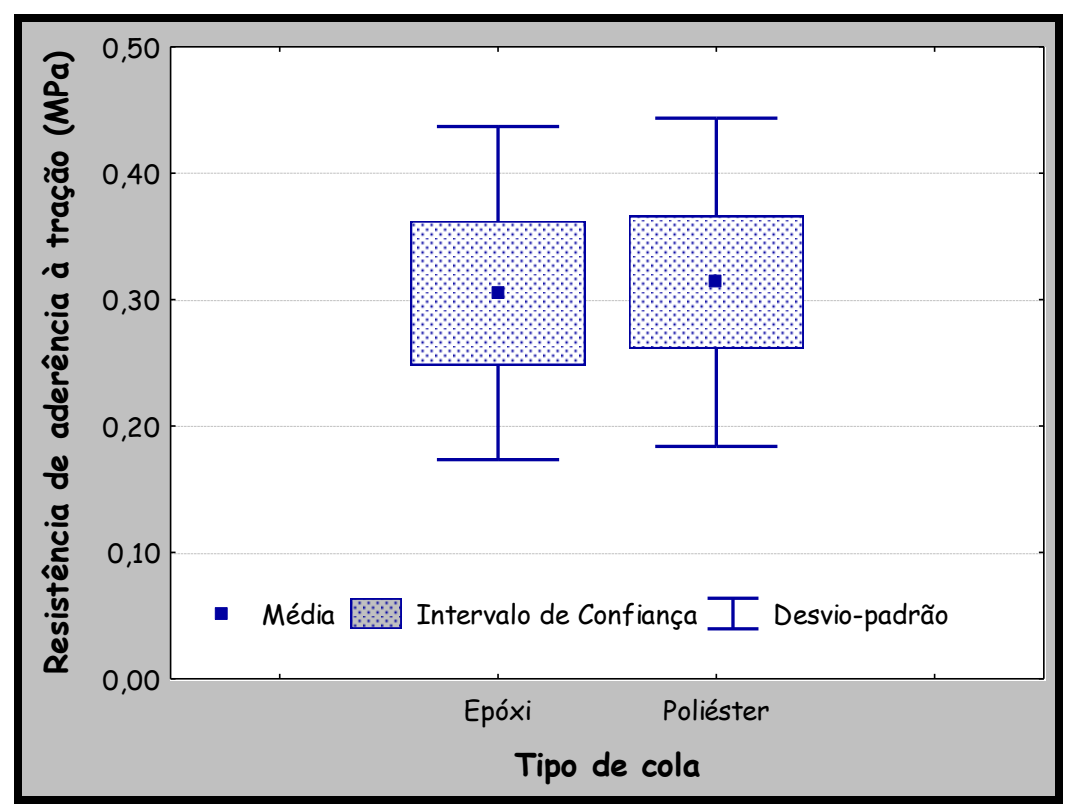

Figura 12 - Distribuição das tensões na interface entre argamassa e substrato para os três tipos de cola estudados com espessura de $5 \mathrm{~mm}$

\section{Influência da excentricidade da pastilha}

As Figuras 13a e 13b apresentam os resultados obtidos na análise numérica com o carregamento sem excentricidade, aplicada no centro da pastilha metálica, e com excentricidade, fora do centro respectivamente.

Com base nestas figuras pode-se observar que as tensões são distribuídas de maneira uniforme ao longo da camada de argamassa, para a carga aplicada sem excentricidade. Na carga aplicada fora do centro da pastilha (Figura 13b), verifica-se um efeito de flexão, que tende a elevar as tensões na parte superior do corpo de prova. Esse acréscimo de tensão tende a diminuir a resistência de aderência do sistema. Embora esse resultado já fosse esperado, ele reforça a importância dos cuidados que se deve ter na preparação e na execução do ensaio, visto que essa excentricidade, ao introduzir tensões maiores que as previstas inicialmente, pode conduzir a interpretações erradas dos resultados.
No que diz respeito às tensões, a carga aplicada no centro de gravidade gera tensões médias da ordem de 0,22 $\mathrm{MPa}$ enquanto que a carga aplicada com excentricidade gera na parte superior tensões de tração equivalentes a $0,86 \mathrm{MPa}$. O acréscimo nas tensões de tração é de $290 \%$. Essas tensões de tração são preocupantes visto que as argamassas de base cimentícia apresentam comportamento frágil. Nesse caso, os resultados não são conclusivos do ponto de vista quantitativo, pois, possivelmente, haveria ruptura à tração antes que esses valores fossem atingidos. Mas como resultados qualitativos, esse valor da tensão de tração mostra como as imperfeições dos ensaios podem modificar e mascarar seus resultados, levando a conclusões errôneas.

A Tabela 10 mostra o resultado da análise de variâncias realizada com os resultados experimentais realizados visando avaliar também o efeito da forma de aplicação da carga. 


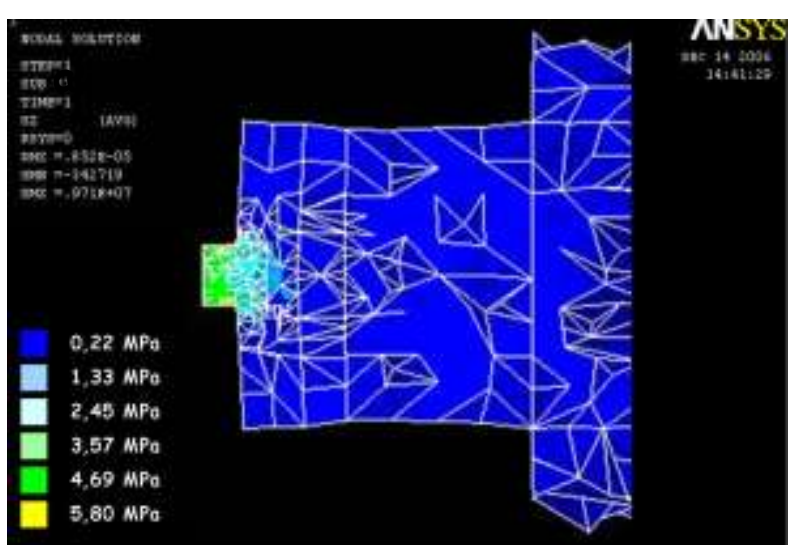

(a)

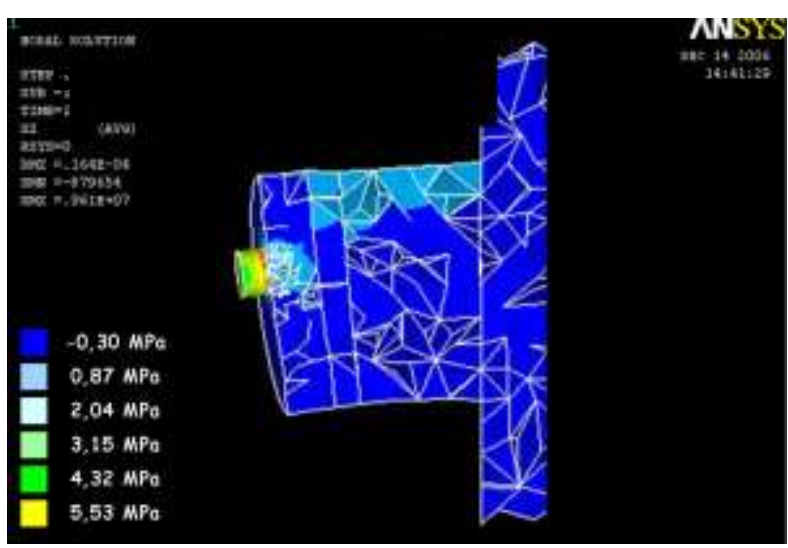

(b)

Figura 13 - Distribuição de tensões ao longo da camada de revestimento observando (a) corpo de prova sem excentricidade e (b) corpo de prova excêntrico

\begin{tabular}{c|c|c|c|c|c|c}
\hline Efeito & SQ & GL & MQ & $\mathbf{F}_{\text {cal }}$ & $\mathbf{F}_{\text {tab }}$ & Resultado \\
\hline Entre Grupos & 0,06 & 1 & 0,06 & 8,64 & 4,02 & Significativo \\
\hline Dentro Grupos (Resíduos) & 0,36 & 54 & 0,01 & - & - & - \\
\hline Total & $\mathbf{0 , 4 2}$ & $\mathbf{5 5}$ & - & - & - & - \\
\hline
\end{tabular}

Legenda:

SQ: soma dos quadrados

GL: graus de liberdade

MQ: média dos quadrados

F: parâmetro de Fisher para o teste de significância dos efeitos

Tabela 10 - Resultados da análise de variância realizada com os valores de resistência de aderência à tração, para verificação da forma de aplicação da carga

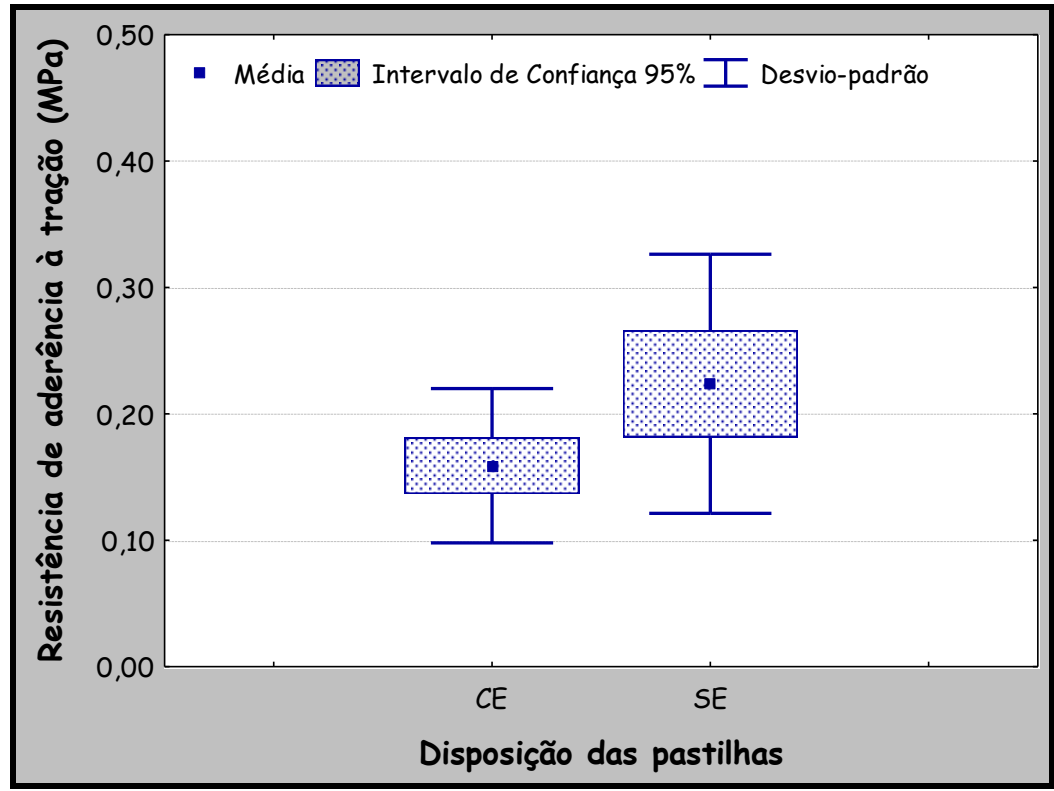

Figura 14 - Valores médios de resistência de aderência à tração e coeficientes de variação para cargas aplicadas com e sem excentricidade, aos $82 \pm 3$ dias 
Esta análise revelou que tanto o modelo fatorial adotado quanto a forma de aplicação da carga (com e sem excentricidade) são estatisticamente significativos a um nível de confiança de $95 \%$, ou seja, o efeito de aplicação da carga possui influência na variabilidade da resistência de aderência à tração.

Na Figura 14 são apresentados os valores médios globais de resistência de aderência em função da disposição das pastilhas.

Analisando a Figura 14, percebe-se que a carga aplicada sem excentridade apresenta valores de resistência de aderência $25 \%$ superior a carga excêntrica, formando inclusive um grupo estatístico isolado.

Conforme visto na etapa de modelagem numérica, isso ocorreu devido ao efeito de flexão que surge nas cargas excêntricas, que aumentam o nível de tensão na parte superior dos corpos de prova, reduzindo a resistência de aderência à tração. Como mencionado, a ruptura também ocorreu antes que o valor de $0,86 \mathrm{MPa}$ (tensão de tração obtida na modelagem numérica) fosse atingido.

\section{Influência do tipo de equipamento}

A análise estatística realizada com os resultados experimentais mostra que o tipo de equipamento constitui-se em uma fonte de variabilidade dos resultados de aderência, exercendo influência significativa sobre estes valores, conforme pode ser visualizado na Tabela 11.

O teste de Duncan indicou a formação de dois grupos distintos: um representado pelo braço de alavanca e outro pelos dinamômetros de tração (Figura 15). O braço de alavanca apresentou menor resistência de aderência, $33 \%$ e $37 \%$ em relação aos equipamentos $\mathrm{A}$ e $\mathrm{B}$, respectivamente, e o menor coeficiente de variação, tal como era esperado.
No que diz respeito aos valores de resistência de aderência, o comportamento do braço de alavanca não correspondeu aos resultados encontrados por Collantes (1998) e Costa, Duarte e Carasek (2000). Esses autores ao comparar o braço de alavanca com dinamômetro de tração obtiveram as maiores médias para o primeiro. Provavelmente, essa diferenciação de resultados ocorreu porque nesta pesquisa os ensaios foram realizados na posição horizontal, sempre em uma mesma altura (110 $\mathrm{cm})$, diferente dos trabalhos citados.

De acordo com Bonaldo, Barros e Lourenço (2005) é difícil estabelecer uma relação entre os valores de resistência de aderência quando empregados equipamentos diferentes para a realização do ensaio. Os autores salientam que medidas feitas por único equipamento proporcionam alta variabilidade. Isto porque ao realizarem ensaios com um dinamômetro de tração (Dyna Z 15) verificaram que em uma mesma situação o equipamento ora apresentava valores elevados ora valores baixos.

Segundo Link (2000) a incerteza oriunda do instrumento de medição é gerada, por exemplo, pela falta de calibração do equipamento e pela velocidade de aplicação da carga. Gil e Rodriguez (2006) salientam que os instrumentos possuem uma precisão finita, ou seja, sempre existe uma variação mínima da magnitude a ser detectada.

Em relação à variabilidade, apesar do braço de alavanca apresentar menor coeficiente de variação, ele é um equipamento obsoleto, dificilmente utilizado para controle tecnológico. Isso foi evidenciado no levantamento de campo, em que nenhum laboratório apontou o uso deste equipamento na atualidade. Por outro lado, esse baixo coeficiente de variação é explicado pela forma de aplicação da carga, que neste equipamento é feita por incrementos de massa, desse modo ao romper considera-se um valor que pode não ser o real, uma vez que o equipamento não permite a leitura gradual.

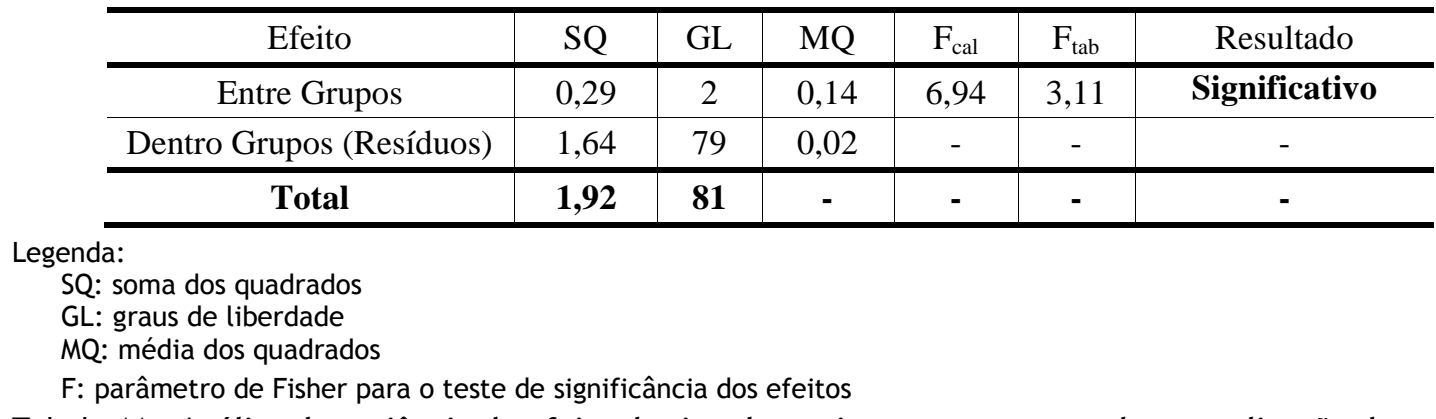

Tabela 11 - Análise de variância do efeito do tipo de equipamento empregado na realização do ensaio de resistência de aderência à tração 


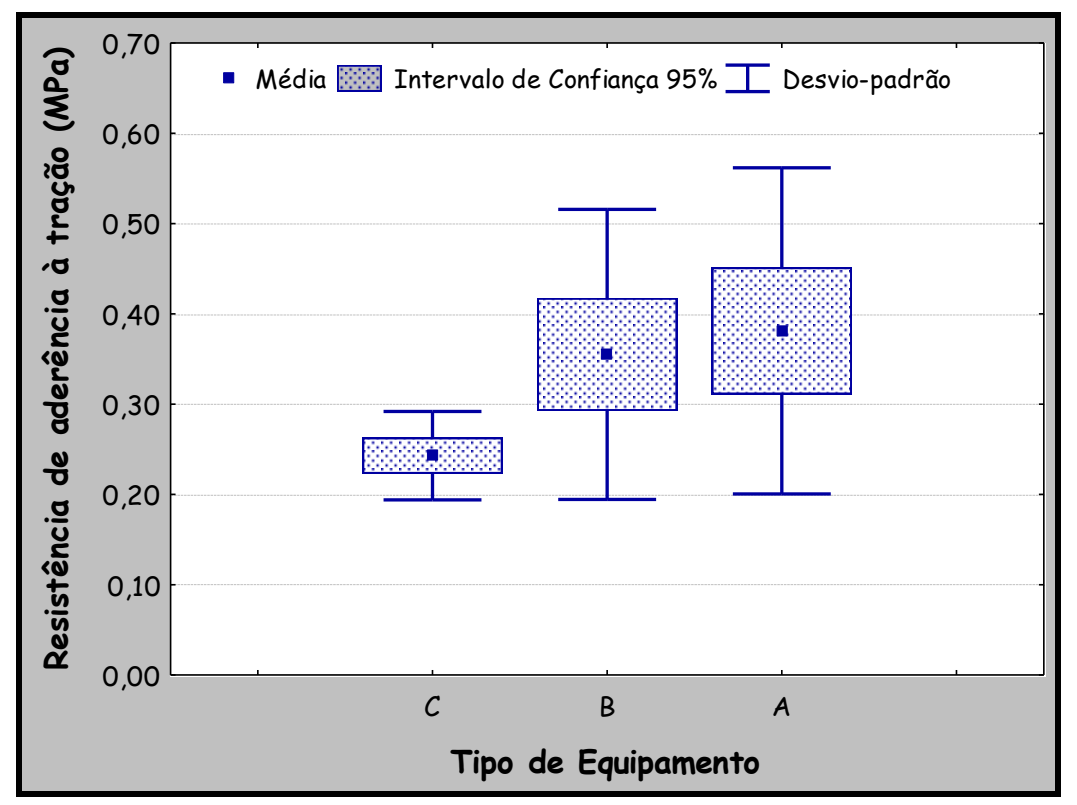

Figura 15- Valores médios de resistência de aderência à tração, aos $82 \pm 3$ dias, observando o comportamento de três equipamentos distintos

\begin{tabular}{c|c|c|c|c|c|c}
\hline Efeito & SQ & GL & MQ & $\mathbf{F}_{\text {cal }}$ & $\mathbf{F}_{\text {tab }}$ & Resultado \\
\hline Modelo & 0,07 & 3 & 0,02 & 5,30 & 2,85 & Significativo \\
\hline (1) Equipamento & 0,00 & 1 & 0,85 & 1,21 & 4,08 & Não-significativo \\
\hline (2) Taxa de carregamento & 0,07 & 1 & 0,07 & 15,32 & 4,08 & Significativo \\
\hline (1)*(2) & 0,00 & 1 & 0,00 & 0,93 & 4,08 & Não-significativo \\
\hline Erro (resíduo) & 0,16 & 38 & 0,00 & - & - & - \\
\hline Total & $\mathbf{0 , 1 7}$ & $\mathbf{4 2}$ & - & - & - & - \\
\hline
\end{tabular}

Legenda:

SQ: soma dos quadrados

GL: graus de liberdade

MQ: média dos quadrados

F: parâmetro de Fisher para o teste de significância dos efeitos

Tabela 12 - Resultados da análise de variância realizada com os valores de resistência de aderência à tração, considerando o tipo de equipamento e a taxa de carregamento

Uma forma de reduzir a variabilidade intrínseca do equipamento é calibrá-los antes da execução dos ensaios e verificar a técnica correta de utilização. Para isso, devem-se observar alguns fatores:

Se há flutuação do instrumento, ou seja, o dispositivo de leitura não inicia no zero ou não fixa o valor após a ruptura, mesmo com a existência do pico.

A peça de encaixe do equipamento à pastilha pode induzir tensões laterais no corpo de prova antes da execução do ensaio ou excentricidade da carga durante a realização do ensaio.

Observar se a manivela do equipamento está funcionando corretamente, porque algumas vezes esta trava, tendo que reiniciar a medição. Com isso, se o corpo de prova não for desprezado romperá por fadiga, não mensurando o verdadeiro valor de aderência.

\section{Influência da taxa de carregamento}

Para a análise da taxa de carregamento foram estudadas duas taxas, máxima (>25N/s) e mínima $(\leq 25 \mathrm{~N} / \mathrm{s}$ ), para os dois dinamômetros de tração utilizados (A e B). A Tabela 12 expõe os resultados da análise de variâncias obtidos para este modelo estudado.

A análise mostra que a velocidade de carregamento exerce influência na resistência de aderência, e confirma o resultado da análise do tipo de equipamento, que não há diferenças significativas entre os dinamômetros de tração empregados. Nota-se também que não houve 
interação entre o tipo de equipamento e a taxa de carregamento adotada.

Os resultados indicaram que a taxa de carregamento máxima proporciona maiores valores de resistência de aderência em relação à taxa mínima adotada (Figura 16). Isso ocorre porque ao transmitir uma carga gradual e lenta há aumento de deformações no sistema. Se a carga for transmitida rapidamente, a ruptura é instantânea, com deformações muito menores. Desse modo, a resistência obtida contém erros introduzidos pelo operador.
Bonaldo, Barros e Lourenço (2005) verificaram a influência da taxa de carregamento $(0,02 \mathrm{MPa} / \mathrm{s}$ e $0,15 \mathrm{MPa} / \mathrm{s}$ ) na resistência de aderência entre dois substratos de concreto. Os resultados indicaram uma tendência de aumento da resistência de aderência com o acréscimo da taxa de carregamento. Resultados com a mesma tendência também foram obtidos por Austin, Robins e Pan (1995).

Os coeficientes de variação não foram alterados com a taxa de carregamento, e sim com o tipo de equipamento empregado, conforme exibe a Tabela 13.

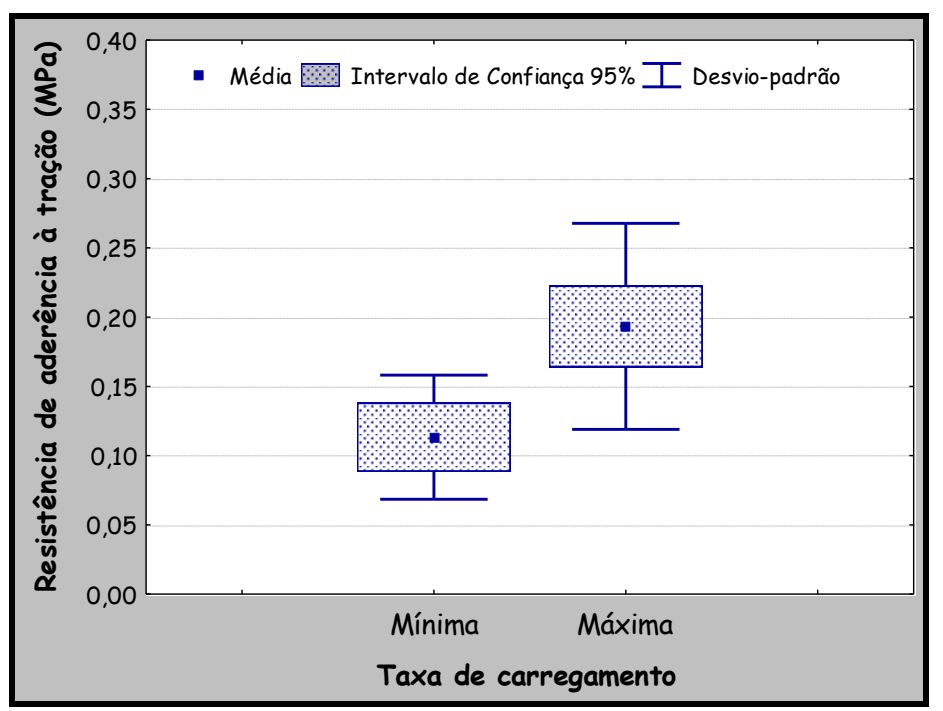

Figura 16 - Valores médios de resistência de aderência à tração e coeficientes de variação para as velocidades de carregamento adotadas para a realização do ensaio aos $82 \pm 3$ dias

\begin{tabular}{c|c|c}
\hline \multirow{2}{*}{ Equipamento } & \multicolumn{2}{|c}{ Taxa de carregamento } \\
\cline { 2 - 3 } & Máxima (> 25 N/s) & Mínima ( $\leq \mathbf{2 5}$ N/s) \\
\hline EA - Consultare & $30,0 \%$ & $29,8 \%$ \\
\hline EB - Dyna Proceq & $47,0 \%$ & $46,8 \%$ \\
\hline
\end{tabular}

Tabela 13 - Coeficientes de variação dos resultados de aderência em função do tipo de equipamento e taxa de carregamento

Vale ressaltar que os equipamentos utilizados não possuíam dispositivo para medir e controlar a velocidade, sendo esta realizada de forma precária com auxílio de um cronômetro, necessitando de duas pessoas para a execução do ensaio. Dessa forma, se o equipamento não possuir este dispositivo recomenda-se à aplicação contínua da carga com uma taxa de carregamento mínima.

No que diz respeito à forma de ruptura, ambos os equipamentos e taxas de carregamento obtiveram ruptura predominante na interface argamassa/substrato.

\section{Conclusões}

O corte realizado com água propiciou menor variabilidade em relação ao corte executado a seco, que pode estar associado com a diminuição de vibrações do corpo de prova durante a execução e menor variação de umidade do sistema.

A geometria e dimensão do corpo de prova, a espessura da camada de cola e a forma de aplicação da carga interferem na distribuição de tensões na interface argamassa-substrato e consequentemente, afetam os valores de resistência de aderência à tração. 
Os corpos de prova circulares apresentam maiores valores de aderência em relação aos quadrados, pois os últimos concentram tensões nas suas extremidades;

O tipo de cola empregado para a realização do ensaio de resistência de aderência à tração não interferiu significativamente nos valores de aderência para o sistema de revestimento analisado.

Os corpos de prova excêntricos proporcionam menores valores de aderência quando comparados com os sem excentricidade, pois estes não estão submetidos a um efeito de flexão inicial.

O emprego de equipamentos com princípios de funcionamento diferentes (alavanca e hidráulicomanual) influencia de modo significativo os resultados de resistência de aderência à tração, tanto os valores quanto o coeficiente de variação. Entretanto, ao comparar dois dinamômetros de tração não houve alteração nos valores de aderência.

Existe uma tendência de aumento da resistência de aderência com o acréscimo da taxa de carregamento, independente do tipo de equipamento empregado.

\section{Referências}

AGIOUTANTIS, Z.; STIAKAKIS, C.;

KLEFTAKIS, S. Numerical Simulation of the Mechanical Behaviour of Epoxy Based Mortars Under Compressive Loads. Computers \& Structures, v. 80, p. 2071-2084, 2002.

\section{AMERICAN SOCIETY FOR TESTING AND MATERIALS. ASTM C 39-01: standard test for compressive strength of cylindrical concrete specimens. Pensilvânia, 2001.}

ANTUNES, R. P. N. Influência da Reologia e da Energia de Impacto na Resistência de Aderência de Revestimentos de Argamassa. 2005. 162 f. Tese (Doutorado em Engenharia) Escola Politécnica da Universidade de São Paulo, São Paulo, 2005.

\section{ASSOCIAÇÃO BRASILEIRA DE NORMAS} TÉCNICAS. NBR 13528: revestimentos de paredes e tetos de argamassas inorgânicas: determinação da resistência de aderência à tração. Rio de Janeiro, 1995.
ASSOCIAÇÃO BRASILEIRA DE NORMAS TÉCNICAS. NBR 15258: argamassa para revestimento de paredes e tetos : determinação da resistência potencial de aderência à tração. Rio de Janeiro, 2005.

AUSTIN, S.; ROBINS, P.; PAN, V. Tensile Bond Testing of Concrete Repairs. Materials and Structures, v. 38, p. 47-56, 1995.

BEER, F. B.; JOHNSTON JÚNIOR, E. R. Resistência dos Materiais. São Paulo: McGRAW-HILL, 1996.

BONALDO, E.; BARROS, J.; LOURENÇO, P. Bond Characterization Between Concrete Substrate and Repairing SFRC Using Pull-Off Testing. International Journal of Adhesion \& Adhesives, v. 25, n. 6, p. 463-474, 2005.

BORTOLUZZO, C. W. Contribuição ao Estudo do Comportamento Mecânico dos Revestimentos de Argamassa. 2000. 238 f. Dissertação (Mestrado em Engenharia Civil) Escola de Engenharia de São Carlos, Universidade de São Paulo, São Carlos, 2000.

CANDIA, M. C.; FRANCO, L. S. Contribuição ao Estudo das Técnicas de Preparo da Base no Desempenho dos Revestimentos de Argamassa. São Paulo: EPUSP, 1998. 13 p. (Boletim técnico)

CARASEK, H. Aderência de Argamassas à Base de Cimento Portland a Substratos Porosos: avaliação dos fatores intervenientes e contribuição ao estudo do mecanismo da ligação. 1996. $285 f$. Tese (Doutorado em Engenharia Civil) - Escola Politécnica, Universidade de São Paulo, São Paulo, 1996.

CARASEK, H. et al. T. Influência da Umidade nas Propriedades dos Revestimentos de Argamassa. In: ENCONTRO NACIONAL DE TECNOLOGIA DO AMBIENTE CONSTRUÍDO, 12., Fortaleza, 2008. Anais... Fortaleza: Antac, 2008.

CHASTRE, C. R. Colunas e Pilares de Betão Armado Reforçados com Compósitos de FRP ou com Betões Poliméricos: varacterização dos materiais: aço, betão, epóxi, compósito de FRP e betões poliméricos. Portugal: UNIC-DTC2, 2005.

CINCOTTO, M. A.; SILVA, M. A. C; CARASEK, H. Argamassas de revestimento: características, propriedades e métodos de ensaio. São Paulo: Instituto de Pesquisas Tecnológicas, 1995. 118 p. (Boletim Técnico 68 IPT) 
COLlanteS, M. C. Contribuição ao Estudo das Técnicas de Preparo da Base no Desempenho dos Revestimentos de Argamassa. 1998. Tese (Doutorado em Engenharia Civil) Escola Politécnica, Universidade de São Paulo, São Paulo, 1998.

COLLANTES, M. C. Contribuição ao Estudo das Técnicas de Preparo da Base no Desempenho dos Revestimentos de Argamassa. 1998. Tese (Doutorado em Engenharia Civil) Escola Politécnica, Universidade de São Paulo, São Paulo, 1998.

COSTA, E. Investigação do Método de Ensaio de Determinação da Resistência de Aderência de Revestimentos de Argamassa. 2007. 205 f. Dissertação (Mestrado em Engenharia Civil) Escola de Engenharia Civil, Universidade Federal de Goiás, Goiânia, 2007.

COSTA, E.; DUARTE, R.; CARASEK, H. Análise da Influência do Tipo de Equipamento e do Operador nos Resultados de Resistência de Aderência dos Revestimentos de Argamassa. In: ENCONTRO NACIONAL DE TECNOLOGIA DO AMBIENTE CONSTRUÍDO, 11., 2006. Florianópolis. Anais... São Paulo: ANTAC, 2006. p. 4061-4072.

\section{EUROPEAN COMITTEE FOR}

STANDARDIZATION. EN 1015-12: methods of test for mortar for mansory, part 12: determination of adhesive strength of hardened rendering and plastering mortars on substrates. Londres, 2000.

GIL, S.; RODRÍGUEZ, E. Teoría de Errores: incertezas de medición. [S.d.]: Notas de aula: Física re-Creativa. Disponível em: <www.fisicarecreativa.com/guias/capitulo1.pdf>. Acesso em: 12 nov. 2006.

GONÇALVES, S. R. C. Variabilidade e Fatores de Dispersão da Resistência de Aderência nos Revestimentos em Argamassa: estudo de caso. 2004. 148 f. Dissertação (Mestrado em Engenharia Civil) -Departamento de Engenharia Civil, Universidade de Brasília, Brasília, 2004.

GOODWIN, J. F.; WEST, W. H. A Review of the Literature on Brick/Mortar Bond. The British Ceramic Research Association, v. 308, p. 23-37, 1982.

LI, G. The Effect of Moisture Content on the Tensile Strength Properties of Concrete. Tese (Doutorado em Engenharia Civil) - University of Florida, Florida, 2004.
LINK, W. Tópicos Avançados da Metrologia Mecânica: confiabilidade metrológica e suas aplicações. Rio de Janeiro, 2000.

MURRAY, I. H. The Adhesion of Cementitious Render to a Brick Background. In: INTERNATIONAL SYMPOSIUM ON LOADBEARING BRICKWORK, 8., Londres, 1983. Proceedings... Londres: Building Material Section of the British Ceramic Society, 1983. 12 p.

NEVES, C. et al. A Influência do Caulim no Comportamento das Argamassas de Revestimento. In: SIMPÓSIO BRASILEIRO DE TECNOLOGIA DAS ARGAMASSAS, 1., 1995. Goiânia. Anais... Goiânia: UFG-ANTAC, 1995. p. 219-225.

PALMER, L. A.; PARSONS, D. A. A Study of the Properties of Mortars and Bricks and Their Relation to Bond. Bureau of Standards Journal of Research, v. 12, p. 609-644, 1934.

SUGO, H. O.; PAGE, A. W.; LAWRENCE, S. J. The Development of Mortar/Unit Bond. In: CANADIAN MASONRY SYMPOSIUM, 9., Hamilton, 2001. Proceedings... Hamilton, 2001.

VAN VLACK, L.H. Princípio de Ciências dos Materiais. São Paulo: Edgard Blücher, 2000.

WEISS, H. Adhesion of advanced Overlay Coatings: mechanisms and quantitative assessment. Surface and Coating Tecnology, v. 71, n. 2, p. 201-207, mar. 1995

\section{Agradecimentos}

As autoras agradecem à Coordenação de Aperfeiçoamento de Pessoal de Nível Superior CAPES e ao Conselho Nacional de Desenvolvimento Científico e Tecnológico $\mathrm{CNPq}$, pelo apoio financeiro à pesquisa, à empresa Carlos Campos Consultoria e Construções LTDA (Sr. Carlos Campos e funcionários), a ABAI (Associação Brasileira de Argamassas Industrializadas), ao Departamento de Metrologia de Furnas Centrais Elétricas S.A, aos professores Sylvia Almeida e Daniel Araújo, aos alunos de iniciação científica da EEC/UFG: Dayana, Gabriel, Gustavo e Nikaelle e a Enga ${ }^{a}$. Deyse Macedo e Luciano Caetano pela colaboração e a viabilização desta pesquisa. 
